\title{
Influência da Família na Formação dos Hábitos Alimentares e Estilos de Vida na Infância
}

\author{
Cláudia Thomé da Rosa Piasetzki, ${ }^{1}$ Eva Teresinha de Oliveira Boff, ${ }^{2}$ \\ lara Denise Endruweit Battisti ${ }^{3}$
}

\begin{abstract}
RESUMO
Objetivo: Analisar a influência da família na formação dos hábitos alimentares e estilos de vida de crianças. Método: Participaram do estudo cem crianças e seus respectivos familiares (cem). Os dados foram coletados por meio de um questionário e avaliação antropométrica. A população do estudo corresponde ao total de alunos, na faixa etária de 2 a 12 anos, das duas escolas municipais do local pesquisado. Resultados: A maioria das crianças (57\%) apresentou eutrofia, mas o número de sobrepeso e obesidade mostrou-se relevante. Tanto as crianças quanto seus familiares fazem uso excessivo de tecnologia digital, indicando sedentarismo. A família mostrou influência no número de refeições das crianças, no consumo de frutas, verduras, guloseimas e na prática de atividade física, assim como no aprendizado sobre alimentação saudável. Conclusão: Os familiares influenciam na formação dos hábitos alimentares e estilos de vida na infância, mas a escola é um espaço importante para promover alimentação saudável.
\end{abstract}

Palavras-chave: Consumo alimentar. Exercício. Cultura. Nutrição da criança.

FAMILY INFLUENCE ON EATING HABITS AND LIFESTYLE DEVELOPMENT IN CHILDHOOD

\section{ABSTRACT}

Objective: To analyze the family influence on eating habits and lifestyle development in children. Methods: In this study participated 100 children and their respective relatives (100). The data were collected from a questionnaire and anthropometric evaluation. The study population corresponds to the total number of students, aged 2 to 12 years old, from two municipal schools where the research took place. Results: Most children (57\%) presented eutrophic, but the overweight and obesity number was relevant. Both children and their families use a lot of digital technology. The family showed influence on the number of children's meals, fruit consumption, vegetables and sweets, and physical activity, as well as learning about healthy eating. Conclusion: The family members influence on eating habits and lifestyle development in childhood, but the school is an important place to promote healthy eating.

Keywords: Food consumption. Exercise. Culture. Child. Nutrition.

RECEBIDO EM: 7/7/2020

MODIFICAÇÕES SOLICITADAS EM: 2/9/2020

ACEITO EM: 23/10/2020

\footnotetext{
${ }^{1}$ Autora correspondente. Secretaria de Saúde e Educação do Município de Bozano/RS. Rua Silvio Frederico Ceccato, № 518 - $98733-000$ - Bozano/RS, Brasil. http://lattes.cnpq.br/0082593947523458. https://orcid.org/0000-0002-2574-313X. claudiapiasetzki@hotmail.com

2 Universidade Regional do Noroeste do Estado do Rio Grande do Sul - Unijuí - Campus ljuí. ljuí/RS, Brasil.

${ }^{3}$ Universidade Federal da Fronteira Sul - UFFS - Campus Cerro Largo. Cerro Largo/RS, Brasil.
} 


\section{INTRODUÇÃO}

O ser humano não nasce com sua cultura pronta, ela é formada por meio do convívio em sociedade (VYGOTSKY, 2013). Do mesmo modo, acredita-se que o ser humano não nasce "viciado" em açúcar, sal, gorduras ou refrigerantes, ele aprende a gostar após experimentar, por influência do meio em que vive e, assim, o consumo recorrente vai se tornando um hábito, podendo até mesmo ser chamado de vício em razão de que o sujeito sente extrema "necessidade" de consumir determinados alimentos.

Laplane e Botega (2010, p. 15) entendem, então, que "o modo de organização social, o modo de vida e a cultura das populações, dos grupos sociais, das comunidades e das famílias, estão estreitamente relacionados".

Para Laplane e Botega (2010, p. 15), "a cultura é algo que se aprende por meio da participação. Desde o nascimento, a criança está imersa em um ambiente social que faz parte de uma determinada cultura sujeita aos movimentos" da sociedade.

De acordo com as autoras, na perspectiva que inspira a psicologia histórico-cultural destaca-se o caráter social da psicogênese do desenvolvimento humano descrito por Vygotsky em suas obras (1984, 1991, 2000). No entendimento de Laplane e Botega (2010), isso significa que a cultura constitui o próprio locus do desenvolvimento, que é concebido por Vygotsky como sendo uma função do ser humano com seu grupo social e não como uma função individual, que é biologicamente programada.

A realização da refeição familiar ou em companhia de amigos também tem uma função social importante, embora isso tenha se modificado nas últimas décadas, em virtude das inúmeras atividades humanas. As pessoas estudam e trabalham em horários diferentes, o encontro é dificultado pelo deslocamento e muitas famílias adotaram o costume de realizar suas refeições enquanto assistem televisão, e "essas práticas são incorporadas e transmitidas pelo habitus que as torna naturais, corriqueiras e até necessárias" (LAPLANE; BOTEGA, 2010, p. 24).

Bourdieu (2017) define habitus como esquemas de percepção, pensamento, prática e ação que são internalizados pelos agentes, que se traduzem em práticas, gostos, opiniões e capitais característicos a um grupo, tudo produzido pelo estilo de vida. $O$ autor afirma que o habitus se forma na primeira socialização do agente, geralmente na família (considerada uma das esferas de socialização mais importantes), e está diretamente vinculado ao pertencimento a uma classe social.
O espaço dos estilos de vida é o mundo social representado e se constitui na relação entre "a capacidade de produzir práticas e obras classificáveis, além da capacidade de diferenciar e de apreciar essas práticas e esses produtos" (BOURDIEU, 2017, p. 162). Para o autor, o gosto por determinados alimentos, portanto, é adquirido pelo contexto de experiências individuais e coletivas, cultural e socialmente construído, e o habitus é responsável por um agente ser detentor de um gosto, pois as condições objetivas de existência associam-se às preferências.

Laplane e Botega (2010) destacam que a alimentação é tema central na cultura e na história da humanidade, revelando-se um símbolo de sobrevivência e de relação entre humanidade e natureza. A alimentação é até mesmo objeto de regras, estando descrita nos livros sagrados de diferentes religiões; "aparece na Bíblia, no Alcorão, no Tripitaka codificada em normas que incluem desde os modos de preparo dos alimentos até as interdições e proibições alimentares" (LAPLANE; BOTEGA, 2010, p. 26-27).

A alimentação envolve práticas que atualizam a história, as tradições e identidades, a economia e a geografia. As práticas alimentares são adquiridas em contextos sociais e culturais determinados. Elas fazem parte do habitus e estão relacionadas ao acesso que diferentes classes e grupos sociais têm aos produtos (alimentos, ingredientes, equipamentos e acessórios para estocagem, conservação e cozimento), à capacidade de consumir, ao prestígio social que ingredientes, produtos e marcas possuem aos olhos de cada grupo social, ao estilo de vida dos indivíduos e famílias, à participação de homens e mulheres no mercado de trabalho e à globalização que torna possível o consumo dos mesmos produtos no mundo inteiro, independente de safras, épocas de plantio e colheita, tempo de produção, etc. (LAPLANE; BOTEGA, 2010, p. 27).

As mudanças políticas, econômicas, sociais e culturais pelas quais o Brasil passou nas últimas décadas, evidenciaram transformações no modo de vida da população. $O$ país cresceu de forma inclusiva, com redução das desigualdades sociais graças à ampliação de políticas sociais na área da saúde, educação, trabaIho, emprego e assistência social (BRASIL, 2014).

Também se observou rápida transição demográfica, epidemiológica e nutricional, apresentando como consequência maior expectativa de vida e redução do número de filhos por mulher, além 
de mudanças importantes no padrão de saúde e consumo alimentar da população brasileira (BRASIL, 2014, p. 5).

Atualmente as principais doenças que acometem os brasileiros deixaram de ser agudas e passaram a ser crônicas, em decorrência do aumento expressivo do sobrepeso e da obesidade em todas as faixas etárias, e as doenças crônicas representam as principais causas de morte entre adultos (BRASIL, 2014). "O excesso de peso acomete um em cada dois adultos e uma em cada três crianças brasileiras" (p. 5).

Vitolo (2015) afirma que uma complexa rede de influências genéticas e ambientais forma os hábitos alimentares. "Existem predisposições genéticas para se gostar ou não de determinados alimentos e diferenças na sensibilidade para alguns gostos e sabores herdados dos pais". Não obstante, "essa influência genética vai sendo moldada ao longo da vida" (VITOLO, 2015 , p. 202), pois, de acordo com Vygotsky (2013), o ser humano constitui-se em sujeito histórico-cultural. Sendo assim, o meio em que está inserido será responsável pela constituição de seus hábitos alimentares e estilos de vida. Também se entende que as práticas alimentares e estilos de vida fazem parte do que Bourdieu denomina de habitus, estes que são adotados quando criança e mantidos no decorrer da vida.

Considerando os argumentos expostos, este estudo tem como objetivo identificar e analisar os hábitos alimentares e estilos de vida de crianças e familiares de duas escolas públicas de um município do interior do Estado do Rio Grande do Sul, na perspectiva de compreender a influência da família para a formação dos hábitos alimentares e estilos de vida na infância.

\section{MATERIAIS E MÉTODOS}

Este trabalho foi desenvolvido por meio de uma pesquisa de abordagem qualitativa e quantitativa. A pesquisa foi realizada em uma Escola de Educação Infantil e em uma de Educação Básica de um município do interior do Rio Grande do Sul. Participaram cem crianças, com seus respectivos pais ou familiares (cem), totalizando 200 participantes.

Após contato com a Direção da escola, a fim de solicitar a autorização para a realização do estudo em suas dependências, fizemos o contato com os sujeitos da pesquisa para a informação dos objetivos do estudo, esclarecimentos acerca da coleta de dados e solicitação de sua participação por meio do Termo de Consentimento e Assentimento Livre Esclarecido (TCALE).
Foram convidados a participar da pesquisa 91 crianças matriculadas no Ensino Fundamental (1으o 5 ano) e 41 na Educação Infantil (Berçário II ao Pré II, com mais de 2 anos de idade) e seus respectivos pais ou familiares.

Os critérios de inclusão foram: apresentar o TCALE assinado pelos pais ou responsáveis e também pela própria criança, e responder os instrumentos da pesquisa de forma completa.

Os dados foram coletados mediante as respostas de questionários e avaliação antropométrica dos participantes. Cada criança recebeu um questionário em sala de aula; as que apresentaram condições de responder sozinhas (crianças já alfabetizadas) o fizeram em sala, as demais levaram para casa, juntamente com um bilhete solicitando que algum familiar as ajudasse a responder (pois o questionário era o mesmo para as crianças de 2 a 12 anos). Os questionários destinados aos pais ou responsáveis foram enviados pelos próprios alunos, contendo as explicações necessárias para o preenchimento adequado. Foi estabelecida uma semana para o retorno dos instrumentos.

Os dados antropométricos de peso da massa corporal e estatura dos escolares foram coletados individualmente em sala apropriada, utilizando técnicas e equipamentos preconizados pela Organização Mundial da Saúde (OMS, 2004). O IMC foi estimado após a verificação do peso da massa corporal $(\mathrm{kg})$ e estatura (m), com avaliação baseada nas Curvas de Referência da OMS (BRASIL, 2020a, 2020b), em escore-Z do IMC/ Idade das Curvas de Crescimento, que constam na Caderneta de Saúde da Criança Menino (BRASIL, 2020a) e na Caderneta de Saúde da Criança Menina (BRASIL, 2020b).

As questões abertas foram analisadas com base na Análise Textual Discursiva (ATD) de Moraes e Galiazzi (2020).

A análise estatística dos dados foi realizada no software $\mathrm{R}$ utilizando frequências absolutas e relativas para as variáveis qualitativas. Para a análise de associação entre variáveis empregou-se o teste de Qui-Quadrado de associação e o Exato de Fisher, considerando o nível de $5 \%$ de significância. As variáveis quantitativas foram apresentadas por média e desvio padrão.

Este estudo foi aprovado pelo Comitê de Ética em Pesquisa, com parecer 33.159. A pesquisa foi desenvolvida de maneira a contemplar todos os preceitos éticos contidos na Resolução 466/12 do Conselho Nacional de Saúde do Ministério da Saúde. 


\section{RESULTADOS DA PESQUISA}

Do total de 232 participantes convidados para a pesquisa, 200 se enquadraram nos critérios de inclusão (crianças $=100$, familiares $=100$ ). Entre os alunos, foram 54 crianças do sexo masculino e 46 do sexo feminino, com idades variando de 2 a 12 anos, com média de idade de 6,9 $\pm 2,4$ anos (Tabela 1 ).

Como nem todos os questionários foram devolvidos, utilizou-se o teste de Qui-Quadrado de aderência para se verificar se a amostra obtida representa a população em estudo, considerando estratificação por faixa etária. $O$ teste não foi significativo $(p=0,999)$, portanto a amostra adere à população de acordo com a distribuição da faixa etária das crianças. Os participantes foram estratificados em três faixas etárias: 2 a 4 anos (19 crianças), 5 a 9 anos ( 65 crianças) e 10 a 12 anos ( 16 crianças) e seus respectivos familiares. Essas faixas etárias justificam-se pelos parâmetros de classificação de escore-Z do IMC/Idade das Curvas de Crescimento, que constam na Caderneta de Saúde da Criança Menino (BRASIL, 2020a) e na Caderneta de Saúde da Criança Menina (BRASIL, 2020b).

Quanto ao estado nutricional, 57 crianças apresentaram eutrofia, 15 sobrepeso, 3 baixo peso e 22 obesidade (Tabela 1). Apesar de a maioria das crianças ter apresentado eutrofia, ainda assim o número de sobrepeso e obesidade mostrou-se relevante, pois $37 \%$ encontraram-se em sobrepeso (15\%) ou obesidade (22\%). Houve associação significativa entre IMC e faixa etária, mostrando maior percentual $(43,8 \%)$ de obesidade na faixa etária entre 10 e 12 anos; nas de- mais faixas etárias o maior percentual está em crianças eutróficas: $68,4 \%$ e $62,9 \%$ para 2 a 4 anos e 5 a 9 anos, respectivamente.

\section{Estilos de Vida}

Quanto ao uso de tecnologia digital, ou seja, o hábito de assistir televisão, jogar video game ou ficar na frente do computador, as respostas das crianças variaram de 1 a 6 horas ao dia, chegando a 12 horas no sábado e 10 horas no domingo (Tabela 2). Para os familiares, a amplitude foi entre 1 hora a 8 horas por dia, chegando a até 9 horas no sábado e 10 horas no domingo. $O$ sábado e o domingo foram indicados como os dias da semana com mais horas destas práticas nos dois grupos (Tabela 2).

Entre as crianças eutróficas, 60\% (27) fazem uso de algum tipo de tecnologia digital, como televisão, video game ou computador, entre 1-2 horas/dia durante a semana, e $29 \%$ (13) usam 3-4 horas/dia durante a semana. Entre as crianças com sobrepeso e obesidade, $50 \%$ (15) usam entre $1-2$ horas e $47 \%$ (14) 3-4 horas/dia. Nos finais de semana, entre as crianças que têm peso normal, 65\% (17) usam de 1-2 horas/dia e $31 \%$ (8) de 3-4 horas/dia. As crianças com sobrepeso e obesidade $50 \%$ (10) usam de $1-2$ horas/dia e $40 \%$ (8) de 3-4 horas/dia. Não se observou uma relação significativa entre IMC e tempo de uso de tecnologia digital, mas pode-se perceber que os eutróficos apresentam menos tempo de utilização de tecnologia digital.

A atividade física é praticada por 79 (80,6\%) crianças e $45(51,1 \%)$ familiares. Entre as crianças que praticam atividade física, 41 (57\%) dos seus familiares também praticam, e entre as crianças que não prati-

Tabela 1 - Distribuição das crianças por sexo e estado nutricional em relação à faixa etária

\begin{tabular}{|c|c|c|c|c|c|}
\hline \multirow[t]{2}{*}{ Características } & \multicolumn{3}{|c|}{ Faixa Etária } & \multirow{2}{*}{$\begin{array}{c}\text { Total } \\
n=100 \\
n(\%)\end{array}$} & \multirow[b]{2}{*}{$P$} \\
\hline & $\begin{array}{c}2-4 \text { anos } \\
n=19 \\
n(\%)\end{array}$ & $\begin{array}{c}5-9 \text { anos } \\
n=65 \\
n(\%)\end{array}$ & $\begin{array}{c}10-12 \text { anos } \\
n=16 \\
n(\%)\end{array}$ & & \\
\hline \multicolumn{6}{|l|}{ Sexo } \\
\hline Masculino & $9(47,4)$ & $35(53,8)$ & $10(62,5)$ & $54(54)$ & $0,700^{\#}$ \\
\hline Feminino & $10(52,6)$ & $30(46,2)$ & $6(37,5)$ & $46(46)$ & \\
\hline \multicolumn{6}{|l|}{ IMC } \\
\hline Baixo peso & $1(5,3)$ & $1(1,6)$ & $1(6,3)$ & $3(3)$ & \\
\hline Eutrofia & $13(68,4)$ & $39(62,9)$ & $5(31,3)$ & 57 (57) & $0,048^{\&}$ \\
\hline Sobrepeso & $4(21,1)$ & $8(12,9)$ & $3(18,8)$ & $15(15)$ & \\
\hline Obesidade & $1(5,3)$ & $14(22,6)$ & $7(43,8)$ & $22(22)$ & \\
\hline
\end{tabular}

Percentual relativo a cada faixa etária; " $\mathrm{p}$ relativo ao teste de Qui-Quadrado; \& $\mathrm{p}$ relativo ao Teste Exato de Fisher.

Três crianças não estavam presentes no dia da avaliação nutricional.

Fonte: As autoras (dados da pesquisa). 
Tabela 2 - Estilo de vida das crianças e familiares de acordo com o uso de algum tipo de tecnologia digital e prática de atividade física em relação à faixa etária

\begin{tabular}{|c|c|c|c|c|c|}
\hline \multirow[b]{2}{*}{ Estilo de Vida } & \multicolumn{3}{|c|}{ Faixa Etária } & \multirow{2}{*}{$\begin{array}{l}\text { Total } \\
\mathrm{n}(\%)\end{array}$} & \multirow[b]{2}{*}{$\mathrm{p}$} \\
\hline & $\begin{array}{c}2-4 \text { anos } \\
\mathrm{n}(\%)\end{array}$ & $\begin{array}{c}5-9 \text { anos } \\
\mathrm{n}(\%)\end{array}$ & $\begin{array}{c}10-12 \text { anos } \\
n(\%)\end{array}$ & & \\
\hline \multicolumn{6}{|c|}{$\begin{array}{l}\text { Crianças - Horas/dia TV, video game ou } \\
\text { computador durante a semana }\end{array}$} \\
\hline $1-3$ horas/dia & $9(56,3)$ & $29(53,7)$ & $5(50)$ & $43(53,8)$ & \multirow[t]{3}{*}{$0,640^{\&}$} \\
\hline $3-5$ horas/dia & $7(43,8)$ & $19(35,2)$ & $5(50)$ & $31(38,8)$ & \\
\hline $5-6$ horas/dia & - & $6(11,11)$ & - & $6(7,5)$ & \\
\hline \multicolumn{6}{|c|}{$\begin{array}{l}\text { Crianças - Horas/dia TV, video game ou } \\
\text { computador final de semana }\end{array}$} \\
\hline 0 horas/dia & - & - & $1(10)$ & $1(2)$ & \multirow{4}{*}{$0,428^{\&}$} \\
\hline $1-3$ horas/dia & $6(75)$ & $20(60,6)$ & $4(40)$ & $30(58,8)$ & \\
\hline $3-5$ horas $/$ dia & $2(25)$ & $11(33,3)$ & $5(50)$ & $18(35,3)$ & \\
\hline 5 horas/dia ou mais & - & $2(6,1)$ & - & $2(3,9)$ & \\
\hline \multicolumn{6}{|c|}{$\begin{array}{l}\text { Familiares - Horas/dia TV, videogame ou } \\
\text { computador durante a semana }\end{array}$} \\
\hline $1-3$ horas/dia & $11(68,8)$ & $32(62,7)$ & $6(60)$ & $49(63,6)$ & \multirow[t]{3}{*}{$0,571^{\&}$} \\
\hline $3-5$ horas/dia & $5(31,3)$ & $13(25,4)$ & $4(40)$ & $22(28,6)$ & \\
\hline $5-6$ horas/dia & - & $6(11,8)$ & - & $6(7,8)$ & \\
\hline \multicolumn{6}{|c|}{$\begin{array}{l}\text { Familiares -- Horas/dia TV, video game ou } \\
\text { computador durante o final de semana }\end{array}$} \\
\hline $1-3$ horas/dia & $4(40)$ & $19(54,3)$ & $5(71,4)$ & $28(53,8)$ & \multirow{3}{*}{$0,614^{\&}$} \\
\hline $3-5$ horas $/$ dia & $6(60)$ & $13(37,1)$ & $2(28,6)$ & $21(40,4)$ & \\
\hline 5 horas/dia ou mais & - & $3(8,6)$ & - & $3(5,8)$ & \\
\hline \multicolumn{6}{|l|}{ Crianças - Atividade física } \\
\hline Sim & $8(42,1)$ & $56(87,5)$ & $15(100)$ & $79(80,6)$ & \multirow{3}{*}{$<0,001^{8}$} \\
\hline Não & $11(57,9)$ & $7(10,9)$ & - & $18(18,4)$ & \\
\hline Às vezes & - & $1(1,6)$ & - & $1(1)$ & \\
\hline \multicolumn{6}{|c|}{ Familiares - Atividade Física } \\
\hline Sim & $7(38,9)$ & $30(52,6)$ & $8(61,5)$ & $45(51,1)$ & \multirow[t]{2}{*}{$0,429^{\#}$} \\
\hline Não & $11(61,1)$ & $27(47,4)$ & $5(38,5)$ & $43(48,9)$ & \\
\hline
\end{tabular}

* Percentual relativo a cada faixa etária; \#p relativo ao teste de Qui-Quadrado; \& $p$ relativo ao teste Exato de Fisher. "Crianças - Horas/dia TV, video game ou computador durante a semana" possui 20 missing (não resposta) entre crianças e 23 entre familiares. "Crianças - Horas/dia TV, video game ou computador final de semana" possui 49 missing entre crianças e 48 entre familiares. "Crianças - Atividade física" possui 2 missing. "Familiares - Atividade Física" possui 12 missing.

$$
\text { Fonte: As autoras (dados da pesquisa). }
$$

cam atividade física $73 \%$ (11) dos seus familiares também não o fazem, não havendo associação significativa $(p=0,064)$, porém indicando relação aproximada.

Observa-se, na Tabela 2, que entre 2-4 anos a proporção $(42,1 \%)$ de crianças que praticam atividade física é menor comparando-se com as outras duas, sendo $87,5 \%$ e $100 \%$ para $5-9$ anos e $10-12$ anos respectivamente, evidenciando uma diferença significativa entre as faixas etárias. Nas demais variáveis analisadas na Tabela 2 não se constatou diferença significativa entre as faixas etárias.

\section{Hábitos Alimentares}

Quanto ao hábito de fazer suas refeições diariamente, 97 crianças costumam fazê-las em casa (1 fora de casa e 2 não responderam), e entre os seus familiares, 83 costumam fazer suas refeições em casa, 2 fora de casa e 3 em casa e fora. Associando o local de refeição entre crianças e seus respectivos familiares, 82 concordam que fazem suas refeições em casa.

Em relação ao costume de ingestão de líquidos durante as refeições, $11(11,1 \%)$ das crianças responderam não ingerir, e entre os pais, $28(31,8 \%)$ não ingerem (Tabela 3). Observa-se, nesta Tabela, que existe 
Tabela 3 - Consumo de líquido durante as refeições entre crianças e familiares em relação à faixa etária

\begin{tabular}{|c|c|c|c|c|c|}
\hline \multirow[b]{2}{*}{ Características } & \multicolumn{3}{|c|}{ Faixa Etária } & \multirow[b]{2}{*}{$\begin{array}{l}\text { Total } \\
\mathrm{n}(\%)\end{array}$} & \multirow[b]{2}{*}{$\mathrm{p}$} \\
\hline & $\begin{array}{c}2-4 \text { anos } \\
\mathrm{n}(\%)\end{array}$ & $\begin{array}{l}5-9 \text { anos } \\
\mathrm{n}(\%)\end{array}$ & $\begin{array}{c}10-12 \text { anos } \\
\mathrm{n}(\%)\end{array}$ & & \\
\hline \multicolumn{6}{|c|}{$\begin{array}{l}\text { Crianças: consumo de líquidos } \\
\text { durante as refeições }\end{array}$} \\
\hline Sim & $17(89,5)$ & $54(84,4)$ & $15(93,8)$ & $86(86,9)$ & \multirow{3}{*}{$0,95^{8} \&$} \\
\hline Não & $2(10,5)$ & $8(12,5)$ & $1(6,3)$ & $11(11,1)$ & \\
\hline Às vezes & - & $2(3,1)$ & - & $2(2,0)$ & \\
\hline \multicolumn{6}{|c|}{$\begin{array}{l}\text { Familiares: consumo de líquidos } \\
\text { durante as refeições }\end{array}$} \\
\hline Sim & $12(66,7)$ & $36(63,2)$ & $10(76,9)$ & $58(65,9)$ & \multirow[t]{3}{*}{$0,123^{8}$} \\
\hline Não & $4(22,2)$ & $21(36,8)$ & $3(23,1)$ & $28(31,8)$ & \\
\hline Às vezes & $2(11,1)$ & - & - & $2(2,3)$ & \\
\hline
\end{tabular}

* Percentual relativo a cada faixa etária; " p relativo ao teste de Qui-Quadrado; \& p relativo ao teste Exato de Fisher. Consumo de líquidos durante as refeições tem 1 missing entre crianças e 12 entre familiares.

Fonte: As autoras (dados da pesquisa).

o hábito de ingerir líquido durante as refeições tanto entre as crianças quanto entre os pais, independentemente da faixa etária.

A maioria (64\%) das crianças e seus familiares tem o hábito de ingerir líquido durante as refeições, porém essa associação não é significativa $(p=0,136)$. Entre as crianças que têm o hábito de ingerir líquido durante as refeições, $71 \%$ (56) dos familiares também apresentam o mesmo hábito.

De acordo com a rotina semanal, o total de refeições que as crianças e familiares costumam fazer habitualmente no dia variou de duas a sete, conforme apresentado na Tabela 4.

Observou-se correlação moderada e significativa $\left(r_{s}=0,46 ; p<0,001\right)$ entre o número de refeições das crianças e seus familiares, afirmando-se que existe relação entre o familiar e a criança, podendo-se inferir sobre a influência dos familiares no número de refeições das crianças. A concordância do número de refeição entre crianças e seus familiares foi maior: $21 \%$ entre 4 refeições ao dia, seguido de $17,1 \%$ das crianças que fazem 5 refeições ao dia e os familiares 4 refeições, e 14,6\% tanto crianças e familiares fazem 3 refeições.

Entre as respostas válidas (86) para a refeição considerada a mais saudável pelas crianças e famílias, $62(72,1 \%)$ respostas tiveram concordância; destes, 56 $(65,1 \%)$ crianças e seus familiares indicaram o almoço, seguido de café da manhã (3) e lanche da tarde (3). 0 almoço teve a maior frequência de indicação como a refeição mais saudável entre as crianças (73\%; $74,5 \%)$ e entre os familiares (68\%; $79,1 \%)$.

Entre as crianças, 80 destacaram algum alimento que não gostam. Entre eles, alimentos dos grupos dos feijões (também conhecido como leguminosas), cereais, raízes, tubérculos, legumes e verduras, frutas, carnes e ovos, leites e queijos, oleaginosas, representando todos os grupos alimentares. Ainda foram citadas sobremesas doces, vinagre (saladas com vinagre), comidas gordurosas, temperos, maionese de batata e condimentos como maionese e mostarda. Concordância de $44 \%$ entre crianças e seus familiares nos alimentos que não gostam, $22 \%$ indicaram alimentos diferentes que não gostam e $34 \%$ não indicaram alimentos individual ou conjuntamente. Entre as crianças que responderam (77) se experimentaram alimentos que não gostam, $70(90,1 \%)$ indicaram que sim.

As respostas referentes aos alimentos preferidos foram bem variadas tanto entre as crianças quanto entre seus familiares, uma vez que foram citados todos os grupos de alimentos. Quanto à preferência por alimentos, $70 \%$ das crianças e seus familiares concordam na preferência e $11 \%$ indicaram alimentos diferentes. Ainda, $19 \%$ das crianças e/ou seus familiares indicaram todos/vários preferidos ou não responderam.

A maioria das crianças (97) e seus familiares (85) responderam comer frutas. Entre os principais motivos indicados pelas crianças é que são saboro- 
Tabela 4 - Número de refeições, preferência de alimentos, motivo comer, opinião sobre alimentação saudável e local onde aprendeu sobre alimentação saudável entre crianças e familiares

\begin{tabular}{|c|c|c|}
\hline Refeição & Crianças n (\%) & Familiares n (\%) \\
\hline \multicolumn{3}{|l|}{ Número de refeições } \\
\hline Duas & $1(1,1)$ & $4(4,7)$ \\
\hline Três & $24(25,3)$ & $21(24,7)$ \\
\hline Quatro & $35(36,8)$ & $39(45,9)$ \\
\hline Cinco & $26(27,4)$ & $15(17,6)$ \\
\hline Seis & $8(8,4)$ & $6(7,1)$ \\
\hline Sete & $1(1,1)$ & - \\
\hline \multicolumn{3}{|l|}{ Refeição mais saudável } \\
\hline Café da manhã & $13(13,3)$ & $11(12,8)$ \\
\hline Colação & $2(2,0)$ & $1(1,2)$ \\
\hline Almoço & $73(74,4)$ & $68(79,1)$ \\
\hline Lanche & $5(5,1)$ & $3(3,5)$ \\
\hline Jantar & $4(4,1)$ & $3(3,5)$ \\
\hline Ceia & $1(1)$ & - \\
\hline \multicolumn{3}{|l|}{ Motivo de comer } \\
\hline Viver & $56(62,9)$ & $61(71,8)$ \\
\hline Fome & $29(32,6)$ & $16(18,8)$ \\
\hline Gula & $2(2,2)$ & $7(8,2)$ \\
\hline Pais mandam & $2(2,2)$ & - \\
\hline Manter peso & - & $1(1,2)$ \\
\hline \multicolumn{3}{|l|}{ Alimentação saudável } \\
\hline $\begin{array}{l}\text { Comer frutas e verduras sem excesso de açúcar/sal/gordura e ingerir alimentos } \\
\text { saudáveis/naturais }\end{array}$ & $56(66,7)$ & $43(56,6)$ \\
\hline Tudo um pouco, de forma equilibrada/quantidades corretas/sem exagero & $26(31)$ & $32(42,1)$ \\
\hline Comer na hora certa & $1(1,2)$ & $1(1,3)$ \\
\hline Comer o que a mãe pedir & $1(1,2)$ & - \\
\hline \multicolumn{3}{|l|}{ Local onde aprendeu alimentação saudável } \\
\hline Em casa & $80(95,2)$ & $50(68,5)$ \\
\hline Nutricionista & $3(3,6)$ & $4(5,5)$ \\
\hline Televisão & $1(1,2)$ & $11(15,1)$ \\
\hline Escola & - & $4(5,5)$ \\
\hline Escola/meios de comunicação & - & $2(2,7)$ \\
\hline Esposa/filha & - & $1(1,3)$ \\
\hline Exemplo doenças causada por alimentação inadequada & - & $1(1,3)$ \\
\hline
\end{tabular}

Número de refeições: 5 missing entre crianças e 15 missing entre familiares. Refeição mais saudável: 2 missing entre crianças e 14 missing entre familiares. Motivo de comer: 11 missing entre crianças e 15 missing entre familiares. Alimentação saudável: 16 missing entre crianças e 76 missing entre familiares. Local onde aprendeu alimentação saudável: 16 missing entre crianças e 27 missing entre familiares.

Fonte: As autoras (dados da pesquisa).

sas $(41 ; 50,0 \%)$ e saudáveis ( $38,46,3 \%)$, e entre os familiares 39 (61,9\%) disseram que são saudáveis e 21 $(33,3 \%)$ indicaram ser saborosas (Tabela 5$)$.

Quanto às verduras, $87(88,8 \%)$ crianças e 83 $(96,5 \%)$ familiares indicaram ingeri-las. Os motivos indicados pela maioria das crianças é que são saudáveis $(28 ; 46,7 \%)$ e saborosas $(27 ; 45,0 \%)$ (Tabela 5$)$. A maioria dos adultos indicou serem saudáveis (40; $58,0 \%$ ) e saborosas (26; 37,7\%). Entre as 57 respostas válidas conjuntamente, $49(86,0 \%)$ concordaram na opinião dos motivos.
Quanto ao consumo de guloseimas (sorvetes, doces, chocolates, salgadinhos e frituras), 76 (77,6\%) crianças ingerem, $20(20,4 \%)$ crianças ingerem às vezes e apenas 2 não ingerem. Entre os familiares, 48 $(57,1 \%)$ indicaram que ingerem, $31(36,9 \%)$ às vezes e 5 não ingerem. Entre as respostas (84) válidas conjuntamente, 55 (65,5\%) concordaram entre crianças e familiares. 
Entre as crianças que responderam (65) o motivo de ingerir guloseimas, a maioria $(61 ; 93,8 \%)$ indicou por serem saborosas (Tabela 5). Entre os familiares que responderam (32), $28(87,5 \%)$ mencionaram serem saborosas (Tabela 5).

Tabela 5 - Motivo do consumo de frutas, verduras e guloseimas entre crianças e familiares.

\begin{tabular}{lcc}
\hline Consumo & $\begin{array}{c}\text { Crianças } \\
\mathrm{n}(\%)\end{array}$ & $\begin{array}{c}\text { Familiares } \\
\mathrm{n}(\%)\end{array}$ \\
\hline Frutas (sim) & 97 & 85 \\
Saborosas & $41(50)$ & $21(33,3)$ \\
Saudáveis & $38(46,3)$ & $39(61,9)$ \\
Mãe oferece & $2(2,4)$ & - \\
Tem em casa & $1(1,2)$ & $3(4,8)$ \\
\hline Verduras (sim) & 87 & 83 \\
Saudável & $28(46,7)$ & $40(58,0)$ \\
Gosta/saborosa & $27(45)$ & $26(37,7)$ \\
Costume/hábito & $5(8,3)$ & $3(4,3)$ \\
\hline Guloseimas & 76 & 48 \\
Saborosas & $61(93,8)$ & $28(87,5)$ \\
Tem em casa & $4(6,2)$ & $1(3,1)$ \\
Gula/desejo & - & $3(9,4)$ \\
\hline
\end{tabular}

$\%$ agrupadas por categorias de frutas, verduras e guloseimas para crianças e para familiares.

Fonte: As autoras (dados da pesquisa).

Na questão sobre se as crianças comem o que querem ou o que os familiares mandam, $47(48,5 \%)$ crianças indicaram que comem os alimentos que os familiares mandam, 27 (27,8\%) comem o que querem/o que gostam, $20(20,6 \%)$ crianças comem o que querem e o que os pais mandam e 3 comem o que querem, porém com consciência de que os pais explicam o que é ou não saudável.

Entre os motivos pelos quais comem, a maioria das crianças indicou comer para viver $(56 ; 62,9 \%)$ ou por fome $(29 ; 32,6 \%)$. Também a maioria $(61 ; 71,8 \%)$ dos familiares mencionou para viver, seguido de 16 $(18,8 \%)$ por fome (Tabela 4). Entre as 81 respostas válidas conjuntamente, $58(71,6 \%)$ crianças e seus familiares concordaram nos motivos pelos quais comem. Entre as discordâncias, observa-se $12(14,8 \%)$ crianças que indicaram comer por fome e seus familiares para viver.

Na questão referente ao que é uma alimentação saudável, $56(66,7 \%)$ crianças responderam que a alimentação saudável está relacionada a comer frutas e verduras sem excesso de açúcar/sal/gordura e ingerir alimentos saudáveis/naturais, e 26 (31,0\%) crianças indicaram comer de tudo um pouco/de forma equilibrada/quantidades corretas/sem exagero (Tabela 4). A maioria dos familiares $(43,56,6 \%)$ respondeu que uma alimentação saudável é comer frutas e verduras sem excesso de açúcar/sal/gordura e ingerir alimentos saudáveis/naturais, 32 (42,1\%) familiares mencionaram comer de tudo um pouco/de forma equilibrada/ quantidades corretas/sem exagero, e $64(87,7 \%)$ das respostas válidas conjuntamente concordaram na opinião da alimentação saudável (Tabela 4).

De acordo com a Tabela 4, a maioria das crianças (80; 95,2\%) aprendeu sobre alimentação saudável em casa com a família. Os familiares também indicaram, na maioria (50; 68,5\%), ter aprendido em casa com a família. Houve $47(75,8 \%)$ respostas concordantes indicando a aprendizagem com a família/casa e 11 $(17,7 \%)$ respostas discordantes, em que as crianças indicaram familiares/casa e os familiares assinalaram televisão.

A maioria das crianças $72(84,7 \%)$ segue o exemplo de seus familiares para se alimentar, 8 e 5 crianças seguem "às vezes" e "não", respectivamente. Das crianças, $45(84,9 \%)$ indicaram: porque meus pais procuram uma alimentação saudável/são um bom exemplo/só comem coisas saudáveis/quero me alimentar corretamente; 5 crianças mencionaram: eu gosto de comer o que eles comem e 3 indicaram: porque são eles que oferecem os alimentos/porque fazemos as refeições juntos.

A maioria dos familiares $(78 ; 78 \%)$ indicou incentivar suas crianças a ter uma alimentação saudável. Dos familiares, $53(80,3 \%)$ incentivam a alimentação saudável pelo motivo da saúde e $13(19,7 \%)$ familiares destacaram para evitar doenças; ainda destes, um complementou: "Porque somos o espelho de nossos filhos, eles copiam o que veem, não adianta apenas falar, tem que criar hábitos saudáveis, pôr os alimentos na mesa" (Familiar 50).

\section{DISCUSSÃO}

Neste estudo foram consideradas as crianças a partir de 2 anos de idade até 12 anos, pois, segundo Vitolo (2015, p. 173), "até os 2 anos de idade, o crescimento reflete as condições de nascimento (gestação) e ambientais (nutrição)".

Na infância quase tudo é relacionado aos hábitos e condutas. É nessa etapa da vida que "é formada a personalidade e são estabelecidos padrões que serão a base do comportamento da criança na idade adulta" (BRASIL, 2018, p. 28). Por isso é preciso

que todos os que estão direta ou indiretamente relacionados ao mundo infantil concentrem seus esforços para que a educação da criança seja a melhor possível. Isso proporcionará a ela uma 
vida saudável em todos os sentidos. É necessário estar consciente de que a saúde é uma peça importante para o equilíbrio das crianças (BRASIL, 2018, p. 29).

Apesar de a maioria das crianças neste estudo ter apresentado eutrofia, o número de crianças com sobrepeso e obesidade mostrou-se relevante, pois mais de um terço delas estavam em sobrepeso ou obesidade, assemelhando-se ao estudo de Melo et al. $(2017$, p. 3), que mostrava que "aproximadamente um terço da população infantil apresentava-se em risco de sobrepeso ou com excesso de peso". Do mesmo modo, o estudo realizado por Machado et al. (2020) mostrou que $40,73 \%$ das crianças estavam acima do peso considerado ideal. Também está de acordo com a afirmação do Guia Alimentar para a População Brasileira, o qual afirma que "o excesso de peso acomete uma em cada três crianças brasileiras" (BRASIL, 2014, p. 5).

De acordo com a World Health Organization (WHO, 2018), a obesidade infantil é um dos mais sérios desafios de saúde pública do século 21 . Crianças com sobrepeso e obesidade tendem a permanecer obesas na idade adulta e estão mais propensas a desenvolver precocemente doenças não transmissíveis, como diabetes e doenças cardiovasculares. $\mathrm{O}$ sobrepeso e a obesidade, assim como as doenças relacionadas, são amplamente evitáveis. Sendo assim, a prevenção da obesidade infantil precisa de alta prioridade (WHO, 2018). “Um dos hábitos que pode prevenir a obesidade infantil é criar o costume, na criança, de alimentar-se bem. Dar-lhe o alimento adequado desde o seu nascimento é a melhor forma de mantê-la com boa saúde" (BRASIL, 2018, p. 29).

Observa-se que a maioria das crianças recebeu ajuda da mãe para responder o questionário. Estudos expõem a influência materna nos hábitos alimentares dos filhos, associando-se ao fato de, na maioria dos casos, ser a mãe quem passa mais tempo com as crianças (OLIVEIRA et al., 2012; NOBRE; BRENTANI; FERRARO, 2016).

Oliveira et al. (2012, p. 383) afirmam que essa influência "pode ser tanto positiva quanto negativa, dependendo da cultura e conhecimentos de cada mãe". Lindsay et al. (2012), em seu estudo realizado com mães de baixa renda em Buenos Aires, na Argentina, identificaram que muitas têm consciência de que a obesidade pode prejudicar a saúde de suas crianças, mas a maioria não tem clareza a respeito das consequências. De acordo com o estudo, as práticas da ali- mentação infantil parecem ter influência do trabalho materno, das pressões familiares, da insegurança alimentar e das preocupações financeiras.

As crianças e suas famílias, neste estudo, apresentaram um excesso de horas de uso de tecnologia digital, bem mais do que um recente estudo canadense (MADIGAN et al., 2019), que investigou o tempo em frente a tela de crianças dos 2 aos 5 anos de idade e identificou que as crianças de 2 anos passavam em média 17 horas por semana em frente a telas e 25 horas aos 3 anos, diminuindo aos 5 anos para 11 horas, quando as crianças começam a ir para a escola.

De acordo com a Sociedade Brasileira de Pediatria (SBP, 2016, p. 2), "estudos científicos comprovam que a tecnologia influencia comportamentos através do mundo digital, modificando hábitos desde a infância, que podem causar prejuízos e danos à saúde".

A Sociedade Brasileira de Pediatria (2016) recomenda que o tempo de uso de tecnologia digital seja limitado a, no máximo, 1 hora ao dia para as crianças entre 2 e 5 anos de idade, ainda na presença dos pais, para ajudar a compreender as imagens. Deve-se estabelecer horários e limites, estimulando a atividade física diária por, no mínimo, 1 hora.

A maioria dos participantes da pesquisa pratica algum tipo de atividade física, sendo estabelecida uma relação de prática comum entre as crianças e suas famílias. Esta apresenta-se como um aspecto positivo, pois "pouca atividade física também pode colaborar para o desenvolvimento de" Diabetes Mellitus Tipo 2 (DM2), "visto que os exercícios físicos aumentam a sensibilidade à insulina e ajudam a prevenir a obesidade" (CUPPARI, 2009, p. 153). No estudo de Minuzzi et al. (2018) observa-se que um comportamento positivo dos pais em relação à atividade física pode ter um impacto igualmente positivo na vida de seus filhos.

Assim como na pesquisa de Melo et al. (2017, p. 3), neste estudo quase todas as crianças realizavam as refeições diariamente com a família na sua casa. 0 Guia Alimentar para a População Brasileira recomenda, sempre que possível, comer em companhia dos familiares, amigos, colegas de trabalho ou escola, assim como compartilhar as atividades domésticas de preparo das refeições. Considera-se que "seres humanos são seres sociais e o hábito de comer em companhia está impregnado em nossa história, assim como a divisão da responsabilidade por encontrar ou adquirir, preparar e cozinhar alimentos" (BRASIL, 2014, p. 96).

Compartilhar o momento da alimentação e as atividades envolvidas constitui-se um modo simples e profundo de criar e desenvolver relações interpes- 
soais, com o comer constituindo parte natural da vida social. "Refeições compartilhadas feitas no ambiente da casa são momentos preciosos para cultivar e fortalecer laços entre pessoas que se gostam". São excelentes oportunidades para as crianças e adolescentes adquirirem bons hábitos e valorizarem a importância de refeições regulares, feitas em ambientes apropriados. Comer acompanhado "ajuda colegas e amigos a se conhecerem melhor e trocarem experiências. Facilita o entrosamento de grupos, aumenta o senso de pertencimento e contribui para o bom desempenho de tarefas do trabalho ou da escola" (BRASIL, 2014, p. 96).

O hábito de ingerir líquido durante as refeições e o consumo alimentar apresentou concordância entre as crianças e familiares. De acordo com Cuppari (2014), a ingestão de líquidos durante as refeições dilui excessivamente o suco gástrico, podendo acarretar dificuldades na digestão.

O número de refeições das crianças e familiares mostrou uma correlação moderada e significativa, permitindo afirmar que o familiar tem influência no número de refeições das crianças. A Sociedade Brasileira de Pediatria (SBP, 2019) orienta que sejam estabelecidos e organizados horários de refeições e de lanches: "recomendam-se cinco ou seis refeições diárias com um intervalo de três horas entre elas. Lembre-se que restringir o número de refeições provoca uma ingestão exagerada de alimentos depois de longos períodos de jejum. Deve-se ainda incentivar o hábito de fazer o desjejum" (p. 105).

A maioria das crianças indicou comer os alimentos que os familiares mandam, ter aprendido o que é uma alimentação saudável em casa com a família e seguir o exemplo de seus familiares para se alimentar. Também os familiares responderam incentivar suas crianças a ter uma alimentação saudável. Entende-se que tanto as crianças quanto seus familiares, em geral, têm uma noção do que é alimentação saudável, porém devemos salientar o fato de que ter o conhecimento não significa praticá-lo. Bento, Esteves e França (2015) observaram, em seu estudo, que os responsáveis pelas crianças tinham uma noção do que é uma alimentação saudável, mas suas práticas alimentares eram inadequadas, estando entre as principais dificuldades apontadas para obter uma alimentação saudável: os recursos financeiros, a falta de tempo e os hábitos alimentares.

Os resultados apresentados neste estudo indicam que a maioria das crianças tem influência da família para o desenvolvimento tanto dos hábitos alimentares quanto dos estilos de vida. A alimentação e estilos de vida das crianças é de responsabilidade dos adultos, sejam eles familiares, professores ou cuidadores.

Segundo Abreu e Kapim (2014, p. 11), “é claro que uma guloseima de vez em quando pode. O que não pode é virar rotina. Se a criança come bem durante a semana, não há nenhum problema em comer balas, chicletes e chocolate nos finais de semana", com moderação. Não se pode ingerir guloseimas todos os dias, ou substituir refeições saudáveis por elas. São necessários equilíbrio e bom senso (ABREU; KAPIM, 2014, p. 11). “Comer de forma saudável é algo que se aprende em casa, e desde cedo. O ideal é que a alimentação equilibrada seja introduzida desde o nascimento, mas é importante saber que nunca é tarde para mudar" (2014, p. 19). A família também deve prestar muita atenção no que come na frente das crianças. Dificilmente elas terão uma alimentação saudável se os adultos ao seu redor comem mal. Antes de querer modificar a alimentação das crianças é preciso que sua família lhe dê bom exemplo. As crianças não vão entender que é preciso ter uma alimentação saudável se os adultos comem mal (ABREU; KAPIM, 2014).

De acordo com Juzwiak (2013), a família representa o primeiro e principal fator de influência sobre os hábitos alimentares das crianças. São os pais ou familiares os responsáveis por ofertar os alimentos para as crianças; desse modo, as escolhas que os pais fazem influenciam nos hábitos alimentares delas.

Vygotsky (2013, p. 103) afirma que a criança desenvolve uma função mediante sua utilização e prática inconsciente e espontaneamente, antes de ter consciência e controle sobre ela. Desse modo, uma criança não pode ser responsabilizada psicologicamente por seus hábitos alimentares e estilos de vida, pois ela os aprende com sua família e os coloca em prática em seu cotidiano, ou seja, ela é influenciada e moldada ao meio em que está inserida. Assim sendo, as práticas alimentares e estilos de vida cotidianos, mesmo ainda inconscientes, vão se repetindo, geralmente influenciados por imitação, e se tornando um hábito.

Os hábitos adquiridos durante a infância e adolescência "são fáceis de serem mantidos na vida adulta e durante o envelhecimento" (BRASIL, 2018, p. 30). "A comida de que gostamos, os temperos que preferimos, o cheirinho que sentimos e que nos enche a boca de água, tudo se refere aos hábitos que adquirimos quando ainda éramos crianças" (2018, p. 30). Desse modo, entende-se porque as práticas alimenta- 
res e estilos de vida formam o que Bourdieu descreve como habitus, estes que são adotados quando criança e seguidos ao longo da vida. como

Bourdieu (2017, p.165) descreve o habitus

princípio unificador e gerador de todas as práticas. O gosto, propensão e aptidão para a apropriação - material e/ou simbólica - de determinada classe de objetos ou de práticas classificadas e classificantes é a fórmula geradora que se encontra na origem do estilo de vida.

O habitus é relacionado por Bourdieu (2017) com o conceito de gosto, que se une com as experiências individuais e coletivas do sujeito. Assim, considera-se que o gosto se dá pelo contexto de experiências individuais e coletivas, cultural e socialmente construídas. Existem

oposições de estrutura semelhantes às que se observam em matéria de consumo cultural e encontram-se, também, em matéria de consumo alimentar: a antítese entre a quantidade e a qualidade, a grande comilança e os quitutes, a substância e a forma ou as formas, encobrem a oposição, associada a distanciamentos desiguais à necessidade, entre o gosto de necessidade que, por sua vez, encaminha para os alimentos, a um só tempo, mais nutritivos e mais econômicos - e o gosto de liberdade - ou de luxo - que, por oposição a comezaina popular, tende a deslocar a ênfase da matéria para a maneira (de apresentar, de servir, de comer, etc.) por um expediente de estilização que exige a forma e às formas que operem uma denegação da função (BOURDIEU, 2017, p. 13).

Se as escolhas dos indivíduos, portanto, são proporcionadas por seus habitus e o estilo de vida resulta das disposições e possibilidades encontradas pelo indivíduo em seu meio, neste contexto é preciso criar o hábito na criança de se alimentar bem, de ter um estilo de vida saudável, simplesmente porque é necessário para manter a qualidade de vida e saúde.

Embora este trate-se de um estudo regional, traz a particularidade de uma região que pode ser distinta do restante do país e que poderá servir de parâmetro para comparações com outras regiões do Brasil.

\section{CONCLUSÃO}

A pesquisa mostra que os familiares são reconhecidos como exemplos a serem seguidos pelas crianças, em especial nos primeiros anos de vida, conforme resultados obtidos das afirmações das crian- ças neste estudo e nos demais pesquisados. Todas as ações dos adultos são observadas e internalizadas pelas crianças, e além do mais, são os familiares os responsáveis por adquirir os alimentos ofertados. Assim, a família influencia a formação dos hábitos alimentares e estilos de vida das crianças.

Mais de um terço das crianças avaliadas neste estudo apresentaram sobrepeso ou obesidade, assemelhando-se com a representação da população brasileira. Não se observou uma relação significativa entre o estado nutricional e o uso de tecnologia digital, mas pode-se perceber que os eutróficos utilizam menos tecnologia digital que os obesos e os com sobrepeso.

Identificou-se uma possível relação entre a prática ou não de exercícios físicos entre pais e filhos, e uma correlação moderada e significativa entre o número de refeições das crianças e seus familiares, podendo-se ressaltar a influência destes últimos.

Notou-se concordância entre crianças e familiares quanto ao consumo de frutas, verduras e guloseimas, podendo afirmar a influência dos familiares nas práticas alimentares das crianças, por serem eles a comprar os alimentos que vão para casa e também referência para suas crianças.

A maioria dos participantes indicou ter aprendido sobre alimentação saudável em casa com a família. As crianças afirmaram seguir o exemplo de seus familiares para se alimentar, e a maioria dos familiares revelou incentivá-las a ter uma alimentação saudável. Os familiares são referência para as crianças, pois elas internalizam o que veem; não adianta só falar, é necessário colocar em prática. Desse modo, enfatiza-se a importância de sensibilizar, por meio de educação nutricional, os familiares responsáveis pelas crianças a manterem hábitos alimentares e estilos de vida saudáveis.

Deve-se considerar, porém, que a partir da idade escolar ampliam-se os meios de convivência social da criança, e a oferta de alimentos e estilos de vida tendem a se modificar. Nessa fase, os hábitos alimentares, com a promoção de uma alimentação e estilos de vida saudáveis, também passam a ser de responsabilidade da comunidade escolar.

\section{REFERÊNCIAS}

ABREU, A.; KAPIM, G. Socorro, meu filho come mal. Rio de Janeiro: LeYa, 2014.

BENTO, I. C.; ESTEVES, J. M. M.; FRANÇA, T. E. Alimentação saudável e dificuldades para torná-la uma realidade: percepções de pais/responsáveis por pré-escolares de uma creche 
em Belo Horizonte/MG, Brasil. Revista Ciência \& Saúde Coletiva, Rio de Janeiro, v. 20, n. 8, p. 2.389-2.400, ago. 2015. Disponível em: http://www.scielo.br/scielo.php?script=sci_ arttext\&pid=S1413-81232015000802389\&Ing=en\&nrm=iso. Acesso em: 5 dez. 2017.

BOURDIEU, P. 1930-2002. A distinção: crítica social do julgamento. Tradução Daniela Kern e Guilherme. F. Teixeira. São Paulo: Edusp; Porto Alegre, RS: Zouk, 2017.

BRASIL. Fundo Nacional de Desenvolvimento da Educação. Jornada de educação alimentar e nutricional. Programa Nacional de Alimentação Escolar. Brasília: FNDE, 2018.

BRASIL. Ministério da Saúde. Caderneta de saúde da criança. Biblioteca Virtual em Saúde do Ministério da Saúde. Disponível em: www.saude.gov.br/bvs. Brasília, DF, 2020a.

BRASIL. Ministério da Saúde. Caderneta de saúde da criança. Biblioteca Virtual em Saúde do Ministério da Saúde. Disponível em: www.saude.gov.br/bvs. Brasília, DF, 2020b.

BRASIL. Ministério da Saúde. Secretaria de Atenção à Saúde. Departamento de Atenção Básica. Guia alimentar para a população brasileira. 2. ed. Brasília: Ministério da Saúde, 2014.

CUPPARI, L. (coord.). Guia de nutrição: clínica no adulto. 3. ed. Barueri, SP: Manole, 2014.

CUPPARI, L. (coord.). Nutrição: nas doenças crônicas não-transmissíveis. Barueri, SP: Manole, 2009.

JUZWIAK, C. R. Era uma vez ... um olhar sobre o uso dos contos de fada como ferramenta de educação alimentar e nutricional. Revista Interface: Comunicação Saúde Educação, 17(45), p. 473-84, 2013.

LAPLANE, A. L. F.; BOTEGA, M. B. S. A mediação da cultura no desenvolvimento infantil: televisão e alimentação na vida cotidiana das famílias. In: NOGUEIRA, Ana Lúcia Horta; SMOLKA, Ana Luiza B. (org.). Questões do desenvolvimento humano: práticas e sentidos. Campinas, SP: Mercado de Letras, 2010.

LINDSAY, A. C. et al. Child feeding practices and house hold food in security among low-income mothers in Buenos. Revista Ciência \& Saúde Coletiva, v. 17, n. 3, mar. 2012.

MACHADO, K. M. C. et al. Avaliação dos Fatores de Prevalência Sobre o Estado Nutricional de Crianças em Idade Escolar. Revista Contexto \& Saúde. v. 20, n. 38, jan./jun. 2020.

MADIGAN, S. et al. Association Between Screen Time and Children's Performance on a Developmental Screening Test. Jama Pediatr., 28 jan. 2019. Disponível em: https://www. ncbi.nlm.nih.gov/pubmed/30688984. DOI: 10.1001/jamapediatrics.2018.5056.

MELO, K. M. et al. Influência do comportamento dos pais durante a refeição e no excesso de peso na infância. Escola Anna Nery, 21(4), 2017.

MINUZZI, T. et al. Relação do comportamento do perfil do estilo de vida de escolares com o de seus pais. Cien. Saúde Colet. [periódico na Internet], mar. 2018. Disponível em: https://www.scielo.br/scielo.php?script=sci_arttext\&pi$\mathrm{d}=$ S1413-81232019000903563. Acesso em: 21 set. 2018.

MORAES, R.; GALIAZZI, M. C. Análise Textual Discursiva. Ijuí: Editora Unijuí, 2020. E-book.
NOBRE, É. B.; BRENTANI, A. V. M.; FERRARO, A. A. Association between maternal life estyle and preschool nutrition. Revista da Associação Médica Brasileira, v. 62, n. 6, set. 2016.

OLIVEIRA, A. S. et al. Hábitos alimentares de pré-escolares: a influência das mães e da amamentação. Revista de Nutrição, Campinas, v. 23, n. 3, 2012.

OMS. Organização Mundial da Saúde. Obesidade: prevenindo e controlando a epidemia global. São Paulo: Roca; 2004. $256 \mathrm{p}$.

SBP. Sociedade Brasileira de Pediatria. - Departamento Científico de Nutrologia. Obesidade na infância e adolescência - manual de Orientação. 3. ed. São Paulo: SBP. 2019. $236 \mathrm{p}$.

SBP. Sociedade Brasileira de Pediatria. Saúde de crianças e adolescentes na era digital, Manual de Orientação, Departamento de Adolescência, n. 1, out. 2016.

VITOLO, M. R. Nutrição: da gestação ao envelhecimento. 2. ed. Rio de Janeiro: Rubio, 2015.

VYGOTSKY, L. S. Pensamento e linguagem. Tradução Jefferson Luiz Camargo. Revisão técnica José Cipolla Neto. 4. ed. São Paulo: Martins Fontes, 2013.

WHO. World Health Organization. Global Strategy on Diet, Physical Activity and Health. Dez. 2018. Disponível em: https://www.who.int/dietphysicalactivity/childhood/en/. Acesso em: 7 dez. 2018. 